\title{
Allergic reactions to insulin: a case report
}

\author{
Rita Aguiar*, Natalia Fernandes, Ana Mendes, Manuel Pereira-Barbosa \\ From 6th Drug Hypersensitivity Meeting (DHM 6) \\ Bern, Switzerland. 9-12 April 2014
}

We present the case of a woman, 47 years old, with type 1 diabetes mellitus. She was regularly treated with detemir insulin (LevemirTM) tid, lispro protamine (Insulin Huma$\log$ Mix 25TM) according with glucose during the day. She noticed the appearance of non-confluent urticariform lesions on the thorax and upper limbs, totalling 20, with a pruriginous papule at the site of subcutaneous insulin Levemir injection after 4-6 hours. The lesions spontaneously regressed after 24 hours of the administrationbiphasic reaction. No other systemic manifestations or triggers were verified. She had partial improvement with a non-sedating $\mathrm{H} 1$ antihistamine. Laboratory evaluation was negative for other autoimmune diseases. Total IgE $<0.1$ $\mathrm{UI} / \mathrm{mL}$, serologies for Cytomegalovirus, Epstein-Barr virus, coxsackievirus, echovirus, HIV $1 / 2$, hepatitis $B / C$ virus were also negative. High serum glycated hemoglobin A1c levels $(7.8 \%)$ were found and apparently correlated with the cutaneous reaction. Skin tests were carried out with Levemir insulin (100U/ ml, 3,5 mg/ml): negative prick test, intradermal skin test $1 / 100,1 / 10$ and pure, showed a papule equal to the initial one but with an extensive surrounding erythema. Humalog insulin $(100 \mathrm{U} / \mathrm{ml}, 3,5 \mathrm{mg} /$ $\mathrm{ml}$ ): negative prick test, intradermal skin test $1 / 100,1 / 10$ and pure, with a papule equal to the initial one without surrounding erythema. Pure protamine sulfate $10 \mathrm{mg} / \mathrm{ml}$ with negative results. Specific IgE: IgE human insulin $<0.10$ $\mathrm{KU} / \mathrm{L}$, bovine insulin $\operatorname{IgE}<0.10 \mathrm{KU} / \mathrm{L}$, porcine insulin $\operatorname{IgE}<0.10 \mathrm{KU} / \mathrm{L}$, human insulin specific $\operatorname{IgG}<2$. Given the results, it was decided to perform skin tests with an alternative Insulin:Lantus Insulin-glargina (100UI/ml-3,64mg) with negative results. Insulin Levemir was suspended and the patient began therapy with Lantus insulin, with no reactions. Glycemic control was achieved after three months. The patient stopped $\mathrm{H} 1$ antihistamine with no recurrence of urticaria. Allergy to insulin analogues is rare and requires early diagnosis, leading to a major therapeutic

Hospital de Santa Maria-Centro Hospitalar Lisboa Norte, Immunoallergology Department, Portugal 